\title{
From Cooperative Innovation to Synergic Innovation: the Road of Industry-University-Research Cooperation Innovation in China
}

\author{
Fan Xu, Huang Wenqian, Lin Yan \\ School of Public Administration, South China University of Technology, Guangzhou, China
}

\begin{abstract}
This paper analyzes the process that Chinese universities came from decentralized cooperative innovation to organized collaborative innovation since the reform and opening up. The paper mentions that the synergic innovation emphasized by the "2011 Plan" should be raised to a new level, i.e. the synergic innovation should be the collaborative innovation with self-organizing nature, which is formed by the spontaneous interaction between innovative elements due to social needs and the internal needs of the innovative actors in the innovation system. The synergic innovation needs to handle the relationship between country's urgent needs and world-class, intrinsic and extrinsic motivation.
\end{abstract}

KEYWORD: synergic innovation; cooperative innovation; university; self-organization

\section{INTRODUCTION}

In May 2012, the Ministry of Education and the Ministry of Finance promulgated "The views of the Ministry of Education and the Ministry of Finance on the implementation of the university's innovation capability enhancement plan". That the "2011 Plan" whose theme is synergic innovation was formally introduced marked the industry-university-research cooperative innovation in China entered a new stage.

Since the reform and opening up, the industryuniversity-research cooperative innovation has been the policy orientation of Chinese government's promoting scientific and technological system reform and higher education system reform. To promote the industry-university-research cooperative innovation has its theoretical basis and practical need. Theoretically, in accordance with the national innovative system theory and regional innovative system theory, the overall innovative capability of a country and a region not only depends on the innovative activities of specific organizations such as enterprises, universities and research institutes, and more importantly, depends on the interaction between them, the interaction between these actors and government departments, and the relation between these actors and system. The production of knowledge and technological innovation is the result of the interaction between the innovative actors in the national innovative system and regional innovative system. The industry-university-research cooperative innovation is the important way of innovative interaction between enterprises and universities. From the perspective of China's scientific and technological innovative practice, the main task of the scientific and technical system reform began in the mid-1980s was to solve the long-term problem of mismatch between science and technology and economy in China. In 1982, China put forward the policy of "economic construction must rely on science and technology, science and technology must serve economic construction". Promoting science and technology better serve economic construction and social development became the main goal of China's science and technology policy. The policy of promoting the combination of science and technology and economy put forwarded by the States has an important impact on China's science and technology innovative activities, and has become a policy foundation to guide Chinese universities to implement industryuniversity-research cooperative innovation. Experiencing changes from decentralized cooperative innovation to organized cooperative innovation, the cooperative innovation of Chinese universities is evolving towards self-organizing synergic innovation. 
2 THE EVOLUTION OF SCIENTIFIC AND

TECHNOLOGICAL INNOVATIVE

ACTIVITIES OF CHINESE UNIVERSITIES SINCE THE REFORM AND OPENING UP

\subsection{The Establishment of the Technology Market Opened Channels for Universities to Cooperate Directly with Enterprises through Outcome Transfer and Technological Consultation.}

The Decision of the scientific and technological system reform made by the Central Committee of the Communist Party in 1985 put forward the reform content of "develop technology market", and in the same year, the first National Technology Achievements Fair was hosted. In 1987, a series of supporting policies concerning technological trading contract management and intellectual property, including the "Technology Contract Law", were issued. These measures led to a high growth of technological trading amount in this period. With the help of technology market, universities in China achieved the transfer of technological achievements in the form of market transactions.

\subsection{The Implementation of the 863 Plan and the Torch Program Expanded the Channels of Science and Technology Innovation in Universities.}

University is the most active actor participating 863 Plan. From the beginning of the 863 plan to the mid1990 s, the number, funding and participants of the 863 Plan's projects undertook by universities ranked first in all departments. For example, in the field of new materials of the 863 Plan's projects, in 15 years from1986-2000, the proportions of the projects undertook by the university, the Chinese Academy of Sciences, industrial institute and corporate were $37 \%, 23 \%, 20 \%, 20 \%$ respectively. University was in the first place. Because the 863 Plan emphasized the participation of enterprises after 2000, the corporate began to dominate in the funding of the 863 Plan.

In order to promote the commercialization and industrialization of high-tech achievements, China began to implement the Torch Plan in 1988. The 863 Plan and the Torch Plan are interconnected, and this makes the outcome of high-tech research and development projects undertook by universities turn into productive forces and generate economic benefits through the Torch Plan's projects. The implementation of these two plans further expands channels of universities' scientific and technological innovative activities.

\subsection{High-tech Industrial Development Zone Becomes the Important Channel of Universities' Contacting External Market.}

In May 1988, Chinese government formally approved the establishment of "Beijing New Technology Industry Development Experimental Zone". Up to 2014, the country approved to establish 113 state-level high-tech industrial development zone, which were generally built around powerful local universities and research institutes, aimed to rely on innovative resources of universities and research institutes, to attract scientific and technological personnel of universities and research institutes to start an undertaking with its scientific and technological achievements, and to promote the transformation of scientific and technological achievements of universities and research institutes.

\section{4 "Industry-University-Research Joint Development Project" Facilitated Organized Cooperative Innovation between Universities and Enterprises.}

Co-organized by the State Economic and Trade Commission, the Ministry of Education and the Chinese Academy of Sciences in April 1992, "The Industry-University-Research Joint Development

Project" aimed to form an mode of industryuniversity-research joint development in which complementary advantages, risk and profit sharing and joint development can be achieved. In 7 years from 1992 to 1999 , more than 10 million enterprises, over 8000 universities and research institutes involved in industry-university-research cooperation. The Industry-University-Research Joint Development Project was the biggest cooperative platform built by the government for universities and other academic institutions to promote their cooperation with industry. The project brought about multi-level connection between universities, enterprises and research institutes. The contact and cooperation between universities and other innovative actors gradually changed from scattered spontaneous economic behavior to organized strategic behavior promoted by the government. The Industry-University-Research Plan of Guangdong Province and the Ministry of Education, Starting in 2005, open a new model of industry-universityresearch cooperation.

\subsection{The Construction of the University Science and Technology Park Promoted the Combination of Universities' Scientific and Technological Resources and Social Resources}

University science and technology parks, which relies on universities of strong research strength and 
makes the combination of universities' intellectual advantageous resources and other social advantageous resources, provide supporting platform and services for transformation of universities' scientific and technological achievements, incubation of high-tech enterprises, training for innovative and entrepreneurial talent and industryuniversity-research cooperation. In 1999, the Ministry of Science and Technology, the Ministry of Education jointly launched the construction of national university science and technology park. The Ministry of Science and Technology, the Ministry of Education identified the first batch of 23 national university science and technology parks in 2001. Until 2010, 86 national university's science and technology parks had been identified. The founding of university science and technology park was the initiative behavior of universities to promote their own research and teaching closely integrate with social and economic development.
2.6 The Implementation of "211 Project" and "985 Project" Strengthened the Combination of Universities and Local Economy and Enterprises.

The construction of high-level universities in the last two decades was the major strategy and policy of higher education development in China. The "211 Project" started in 1993 and "985 Project" started in 1999 fully reflected the national goals of higher education reform and development and have played a positive role in China's higher education development and universities' science and technology development. The funds needed by "211 Project" and the "985 Project" are raised together by central government, competent authorities, local government and universities. The competent authorities and local government were required to support funds. Therefore, the needs of local economic construction are the important basis must be taken into account for universities' choice of disciplinary development, scientific research and talent cultivation, so that the links between universities and local businesses were strengthened.

Table1 The capital source of some universities in the first phase of 985 project construction (unit: One hundred million yuan)

\begin{tabular}{|l|l|l|l|}
\hline & The total money & $\begin{array}{l}\text { funding from the ministry } \\
\text { of education }\end{array}$ & $\begin{array}{l}\text { funding from Province and city } \\
\text { government }\end{array}$ \\
\hline South China university of technology & 4 & 2 & 2 \\
\hline Sun yat-sen university & 12 & 3 & 9 \\
\hline Nanjing university & 12 & 6 & 6 \\
\hline Wuhan university & 8 & 4 & 4 \\
\hline
\end{tabular}

Data sources: the ministry of education of China

\section{3 “2011 PLAN" OPENED A NEW STAGE OF UNIVERSITIES' COLLABORATIVE INNOVATION}

Generally speaking, Chinese universities came through the process from decentralized cooperative innovation to organized collaborative innovation since the reform and opening up. The industryuniversity-research cooperation innovation has made gratifying achievements, expanded universities' social service functions, greatly strengthened the linkages of universities and enterprises. At the same time, we should noted that industry-universityresearch cooperative innovations in the past 20 years mostly were the cooperation between single university and single enterprise, rarely the cooperation between universities and research institutes, university and university, research institutes and enterprises. For example, patent cooperative applications reflect the cooperative innovative status of each innovative actor to some extent. From 1985 to 2003, the number of national invention patent cooperative application was 44,190, accounting for $7.5 \%$ of the total national invention patent applications in the same period, in which the most were the joint application between individual and individual, enterprise and enterprise, respectively accounted for $42.3 \%$ and $32 \%$ of all invention patent cooperative applications in this period. The proportion of universities' invention patent cooperative application was low: joint application of universities and enterprises accounted for $7.4 \%$, joint application of universities and research institutes accounted for $1.25 \%$, joint application between university and university accounted for only $0.58 \%$ in all invention patent cooperative applications. Joint application of enterprises and research institutes accounted for only $5 \%$ in all invention patent cooperative applications. And there were high unit concentration and high technological concentration in universities' invention patent cooperative applications, which focused on some of the units and technological fields, and the quality of cooperative application invention patent was lower than the average of all invention patents[1] That is, the synergistic effect of all kinds of innovative actors and a variety of innovative elements did not occur. The cooperation 
between universities and enterprises was universities' behavioral selection under external forces of policy, did not form the self-interactive self-organization behavior based on the internal needs of innovation actors in the innovation system so that the effect of collaborative innovation was affected. The synergistic innovation stressed by "2011 Plan" needs to elevate the industry-universityresearch cooperative innovation to a new height.

According to the theory of dissipative structure and the theory of synergetics, synergistic effect is the phenomenon that ordered structure is generated from chaos in an open system far from equilibrium by coherent actions between elements under the trigger of fluctuations, in the case of the system exchanging substance or energy with external environment. Selforganization is the most important feature of synergetic phenomenon, that is, the generation of synergistic effect needs external matter, energy and information, but this is only an external condition, the synergistic effect is not formed through the direct intervention of external forces, but from the nonlinear interaction between the elements in the system, and has the characteristics of spontaneity. The difference of organization and self-organization is that the former has a clear external command, while the latter has no clear external command and only has certain external conditions [2][3]. Hence, the synergistic innovation emphasized by "2011 Plan" should rise to a new level: the synergistic innovation should be the collaborative innovation formed by the spontaneous interaction between innovative elements in an innovation system due to innovation actors' internal needs and under the influence of the social needs, and is a self-organizing behavior. The demand-oriented mentioned by the "2011 Plan" should be the combination of social needs and disciplines' needs. Universities need to respond to the needs of the community, and also need the support of the community, but synergistic innovation should not be just universities and other innovative actors' passive response to the social needs, but should be the collaborative innovation behavior of universities' meeting social needs initiatively under the drive of internal needs, by turning social needs into intrinsic needs through choice and absorption.

\section{THINKINGS ON SYNERGISTIC INNOVATION}

\subsection{Correctly Handle the Relationship between Country's Urgent Needs and World-Class Research and Take into Account both Social and Academic Values.}

The "2011 Plan" takes "country's urgent needs and world-class research" as the fundamental starting point, and focuses on original innovation and the effectiveness of solving major national needs. National urgent need is a national goal, and worldclass research is an academic goal, they may be consistent, and may not be fully consistent. National urgent needs reflect the needs of the community, and world-class research is the need of discipline. In the current social environment, it is easy to lead to seek quick success and instant benefits if only national urgent needs are stressed, and it is easy to lead to the separation of universities' researches from social needs if only the disciplines' goal of world-class is emphasized. Therefore, we should both emphasize the national urgent needs and world-class research, take into account the social needs and discipline needs, social value and academic value.

\subsection{Correctly Handle the Relationship between Internal Motivation and External Motivation.}

In regard to universities' synergistic innovation, the governmental policy is an external factor, the sustainable development of higher education and universities' science and technology can only be endogenous development, the key is to rely on the internal driving force of universities' developing higher education and science and technology, and this internal driving force is universities' teachers and research institutes' relentless pursuit of scientific knowledge and technological knowledge, the diligent exploration for unknown science and technology fields, the spade husbandry of personnel training. The successful governmental policy should be able turn the policy's external motivation into the universities' inner motivation, guide the universities to make personnel training and scientific research as their mission, guide teachers to make teaching and scientific research as their own internal needs, and take on social services on this basis so as to achieve the unification of inter value and external value, rather than to accept teaching and research tasks in order to fight for projects, to get funds and to improve universities' ranking. Only in this way can we achieve the continuous innovation in universities.

\section{REFERENCES}

[1] Mao Hao, Xie Xiaoyong. Cooperative application for Invention Patent: Problems and Suggestions. China's Investment in Science and Technology, 2008 (2): 33-35.

[2] Hermann Haken. Synergetics: the wonders of nature constitution. Shanghai: Shanghai Translation Publishing House, 2001:6-11, 51-57.

[3] Shen Xiaofeng. Theory of dissipative structure Shanghai: Shanghai People's Press, 1987:36-44. 